\title{
Increased Risk of Graves'ophthalmopathy in Patients With Increasing TRAb After Radioiodine Treatment and the Impact of CTLA4 on TRAb Titres
}

\section{Bushra Shahida}

Lund University, Department of Clinical Sciences Malmö, Diabetes and Endocriology

Kleoniki Tsoumani

Department of Endocrinology, Lund University, Department of Clinical Sciences, Skåne University Hospital Malmö and Lund

\section{Tereza Planck}

Department of Endocrinology, Lund University, Department of Clinical Sciences, Skåne University Hospital Malmö and Lund

\section{Vijayachitra Modhukur}

Lund University, Department of Clinical Sciences Malmö, Diabetes and Endocrinolog

\section{Pernilla Asp}

Skåne University Hospital Lund: Skanes universitetssjukhus Lund

\section{Anna Sundlov}

Skåne University Hospital Lund: Skanes universitetssjukhus Lund Jan Tennvall

Lund University Clinical Research Centre: Lunds universitet Clinical Research Centre, department of Oncology

\section{Peter Åsman}

Lund University Clinical Research Centre: Lunds universitet Clinical Research Centre

\section{Ola Lindgren}

Department of Endocrinology, Lund University, Department of Clinical Sciences, Skåne University Hospital Malmö and Lund

Mikael Lantz ( $\sim$ Mikael.Lantz@med.lu.se)

Skåne University Hospital, Lund University

\section{Research Article}

Keywords: Graves' disease, TRAb, anti-TPO, anti-TG, radioiodine, CTLA-4

Posted Date: September 20th, 2021

DOl: https://doi.org/10.21203/rs.3.rs-883457/v1 
License: (c) (i) This work is licensed under a Creative Commons Attribution 4.0 International License. Read Full License

Version of Record: A version of this preprint was published at Endocrine on December $2 \mathrm{nd}, 2021$. See the published version at https://doi.org/10.1007/s12020-021-02952-2. 


\section{Abstract}

Introduction. Treatment of Graves' disease (GD) with radioiodine increases the risk of developing Graves' ophthalmopathy (GO) but the link between thyroid and orbital tissue remains undefined.

The aim was to investigate the relationship between $\mathrm{GO}$ and TRAb after treatment with radioiodine and to define the impact of risk genes.

Methods. GD patients without ophthalmopathy or previous treatment with radioiodine were prospectively included at treatment with radioiodine for hyperthyroidism. A follow-up was performed one year later for registration of GO development. The study was performed at a University Hospital Clinic; referral center of all patients treated with radioiodine in the south of Sweden. The main outcome measures were development of TRAb, anti-TPO, anti-TG after three months and GO after 12 months and relationship to the genetic background (HLA, CTLA-4, CYR61).

Results. Three months of radioiodine TRAb increased in two thirds of patients $(p<0.0005)$ but not in the other third. Anti-TPO was associated with TRAb $(R=0.362, p<0.0001)$ but not anti-TG. At follow-up one year later $(n=204) 32$ patients developed $G 0$ with a proportion of $70 \%$ in the group increasing in TRAb and $30 \%$ in the group with unchanged or lower TRAb ( $p$-value $<0.0005$ ). Patients with GO had higher levels of TRAb than patients without GO. CTLA-4 (rs231775 SNP) was significantly $(p<0.005)$ associated with TRAb levels above the median three months after radioiodine.

Conclusions. The increase in TRAb after treatment with radioiodine is associated with $\mathrm{GO}$ and a genetic variation in CTLA-4 is associated with higher levels of TRAb.

\section{Introduction}

In Graves' disease (GD) immunocompetent cells infiltrate thyroid tissue with the release of TSH-receptor stimulating antibodies (TRAb) resulting in hyperthyroidism. The triggering of the autoimmune response depends on the interplay of genetic [1,2] and environmental factors [3]. A strong risk factor is tobacco smoking which results in higher TRAb at diagnosis of GD and during treatment with thiamazole than nonsmokers $[3,4]$

Independent of smoking it has been shown that higher TRAb increases the risk of GO both at and after diagnosis of GD $[5,6]$. Treatment of GD with radioiodine is a risk factor for the development of GO and might be mediated by activating TRAb [7]. Laurberg et al have shown that treatment with radioiodine results in an increase of TRAb with a maximum after 3 months which is in contrast to treatment with antithyroid drugs (ATD) or thyroidectomy, where TRAb slowly declines without a prior increase [8]. It has been suggested that the increase in TRAb after radioiodine treatment is mediated by a transient release of thyroid antigens $[9,10]$. However this assumption has been difficult to confirm. In some patients the increase in TRAb persists for several years, indicating the existence of other mechanisms involving the activation of specific immunocompetent cells or a prolonged effect of radioiodine on immunocompetent 
cells. Irradiated Hashimoto lymphocytes have been studied in vitro, and it was proposed that irradiated lymphocytes of the thyroid are important in the synthesis of autoantibodies in response to 131-lodine [11].

We have previously identified immediate early genes (IEGs) to be overexpressed in orbital tissue from patients with severe GO [12]. These genes have later been investigated for the presence of gene polymorphisms and we found an association of CYR61 with GD and GO, and an increased risk for GO in smokers (OR 4.75) [13]. Later, in a microarray analysis of human orbital tissue, we showed that the IEGs exhibited higher expression in smokers compared to non-smokers [14]. Cytotoxic T-lymphocyte antigen (CTLA-4) and human leukocyte antigen (HLA) are other genes with known association to GD [2]. There are no known genes associated only with GO.

In a previous study on the treatment of GD patients with radioiodine we have defined one group with increases in TRAb, thyroid peroxidase antibodies (anti-TPO), thyroglobulin antibodies (anti-TG), and another group with no increase of these thyroid antibodies after treatment with radioiodine [15]. We have now increased the number of patients and followed these patients for at least 1 year.

The present study aimed to investigate the relationship between TRAb and the development of GO and to define the impact of risk genes.

\section{Material And Methods}

\section{Subjects and treatment}

Treatments with 131-iodine in Skåne County (inhabitants 1360000 December 31 2019) are centralized to the department of Oncology in Lund where all patients with hyperthyroidism are referred if the patient's ordinary clinician decides that radioiodine is the best choice of treatment.

This prospective observational study included GD patients, without GO, admitted to the Department of Oncology for treatment with radioiodine from August 2016 until August $2018(n=204)$ and follow up one year later for development of GO

TRAb, anti-TPO and anti-TG were measured before and 3 months after 131-iodine treatment and the fold changes were calculated.

Patients without GO at radioiodine treatment but with with risk factors for the development of GO were prescribed (by the treating clinician), prophylaxis with prednisolone. These patients $(n=45)$ received prednisolone $30 \mathrm{mg}$ per day for 1 month and after that the dose was slowly decreased during the next 2 months and stopped after 3 months.

The patients were classified as having GD based on clinical signs, the presence of TRAb, and/or a diffuse uptake on thyroid technetium scintigraphy; all patients performed this investigation. One year later all patients were screened for the development of GO (or not) by an endocrinologist or an ophthalmologist at 
their home clinic in Skåne. All patients received a questionnaire and DNA swab for self-collection of DNA from the buccal mucosa which 130 out of 204 patients accepted and sent in an envelope to our research laboratory. DNA was amplified and analyzed for the presence of polymorphisms in known risk genes for GD and GO (CTLA4, HLA-DRB, CYR 61)

In total 204 patients not previously treated with radioiodine were included. The following parameters were registered; age, sex, born in Sweden, tobacco smoking, GD and GO duration, and treatment with corticosteroids (Table 1). As a clinical routine 120 Gray was used but in some patients up to 300 Gray was administered if the aim was to decrease the risk of relapse. Methimazole or propylthiouracil with or without L-thyroxine was used in some patients prior to radioiodine and was stopped 2 weeks before administering of 131-iodine. The ALARA (as low as reasonably achievable) principle was used when defining the activity needed to achieve the described doses and the activity $(\mathrm{MBq})$ was estimated by use of the following formula: Dose (D) x Mass (m) / $0.043 \times$ uptake day zero (U0) $x$ effective half- life (Teff). $\mathrm{UO}$ and Teff were calculated from the iodine uptake at $24 \mathrm{~h}$ and 7 days. The thyroid mass was calculated from $99 \mathrm{mTc}$-pertechneate scintigraphy.

Table 1

Changes in TRAb after treatment with radioiodine and relation to clinical parameteters.

\begin{tabular}{|c|c|c|c|}
\hline Fold change TRAb & $\nabla 1.1$ & $\geq 1.1$ & P value* \\
\hline Patients (\%) & $57(31)$ & $125(69)$ & \\
\hline Females (\%) & $45(79)$ & $97(78)$ & 0.84 \\
\hline Age males and females, years & $56 \pm 17$ & $54 \pm 16$ & 0.67 \\
\hline Age females, years & $54 \pm 17$ & $52 \pm 16$ & 0.49 \\
\hline Smokers (\%) & $8(14)$ & $31(25)$ & 0.10 \\
\hline Born outside Sweden (\%) & $12(21)$ & $35(28)$ & 0.32 \\
\hline Treatment with Corticosteroids (\%) & $41(73)$ & $79(63)$ & 0.23 \\
\hline Treatment with $\otimes 120$ Gy & $10(18)$ & $21(16)$ & 0.99 \\
\hline Duration of GD, months & $12(5-25)$ & $8(3-33)$ & 0.48 \\
\hline Primary treatment with ATD (\%) & $37(65)$ & $70(56)$ & 0.33 \\
\hline Duration of GO, months & $6 \pm 6$ & $5 \pm 3$ & 0.52 \\
\hline Treatment with Corticosteroids in GO patients & $2(22)$ & $4(17)$ & 0.99 \\
\hline GO Smokers & 0 & 2 & 0.99 \\
\hline
\end{tabular}

The proportion of absorbed doses used were distributed as follows: 120 Gy $(78 \%),>120-300$ Gy (22\%) 
In total 5 single nucleotide polymorphisms (SNPs) were genotyped in 127 patients (Table 2); Two SNPs, rs1378228 and rs12656618, in CYR61 and two in CTLA4, rs3087243 and rs231775, were chosen for analysis based on previous studies on GD and GO (13) Also, a tag SNP, rs6457617, HLA Class II, DR Beta 1 (HLA-DR-DQQ was analyzed as previously described (16).

Table 2

Characteristics of genotyped patients

\begin{tabular}{|lll|}
\hline & TRAb (IU/L) \ median (15 IU/L) & TRAb (IU/L) $\geq$ median (15 IU/L) \\
\hline N & 57 & 60 \\
\hline Sex & $55 \pm 18$ & $54 \pm 15$ \\
Male & & $15(25)$ \\
Female & $13(23)$ & $45(75)$ \\
\hline Ethnicity & $44(77)$ & $47(78)$ \\
Born in Sweden & & $7(12)$ \\
Born in Europe & $44(77)$ & $6(10)$ \\
Born outside Europe & $7(12)$ & $10(17)$ \\
\hline Smokers & $6(11)$ & $39(65)$ \\
\hline Non-Smoker & $12(21)$ & $11(18)$ \\
\hline Missing & $41(72)$ & $31(24-39)$ \\
\hline *TRAb IU/L (median 15 IU/L) & $6(3-9)$ & \\
\hline Missing Information on 10 patient & $4(7)$ & \\
\hline Values expressed are means $( \pm$ SD) and presented as $\mathrm{n}(\%)$ unless otherwise stated & \\
\hline
\end{tabular}

DNA was collected for genotyping by using buccal swabs, then extracted using QiAamp UCP DNA Micro Kit (Qiagen, Sweden) and amplified using Repli-g Screening Kit (Qiagen, Sweden). SNPs were genotyped by TaqMan Allelic Discrimination Assay using the Quantstudio 7 Flex system (Applied Biosystems by Life Technologies, Sweden).

The minor allele frequency (MAF) for all SNPs was $>0.05$. One SNP (rs12756618 in CYR61) failed the Hardy-Weinberg equilibrium and was excluded from the analysis.

The standard statistical analysis approach was used to find association of TRAb < median / TRAb > median and GO / no GO association. A linear regression model was used with smoking and gender as 
covariates. The data are presented as odds ratios (ORs) with 95\% confidence intervals (Cls). The p-values are based on additive models for the genetic variants. All genetic analyses were performed using PLINK version 1.0 (http://pngu.mgh.harvard.edu/ purcell/plink/index.shtml).

\section{Assays for antibodies}

TRAb was measured with a competitive Electro Chem Luminiscens Immunoassay (ECLI) according to the manufactures instructions (Roche). The limit of detection was $0.3 \mathrm{IU} / \mathrm{L}, \mathrm{CV} 5 \%$ at $16 \mathrm{IU} / \mathrm{L}$. Cut off for a positive value of TRAb was $>1 \mathrm{kIU} / \mathrm{L}$.

Anti-TPO titer was measured with a competitive sandwich ELISA (Roche) according to the manufactures instructions (detection limit $5 \mathrm{kIU} / \mathrm{L}, \mathrm{CV} 11 \%$ at $34 \mathrm{kIU} / \mathrm{L}$. The cutoff for a positive value of anti-TPO was $>34 \mathrm{kIU} / \mathrm{L}$.

Anti-TG was measured with a competitive sandwich ELISA (Roche) according to the manufactures instructions (detection limit $10 \mathrm{kIU} / \mathrm{L}, \mathrm{CV} 10 \%$ at $73 \mathrm{kIU} / \mathrm{L}$ ). The cutoff for a positive value of anti-TG was $>115 \mathrm{kIU} / \mathrm{L}$.

Samples were analyzed in routine clinical laboratory at the Department of Clinical Chemistry in Malmö and Lund.

\section{Statistics}

The fold changes of thyroid antibodies were calculated. A change of 1.1 or more was judged as increase and if lower than 1.1 the change was judged as unchanged or decreased. The t-test (continuous variables), chi-square test (categorical variables), and bi-nomial test were used to assess the statistical significance of differences between the groups. Linear regression analysis was used to study the correlations between the parameters fold change of TRAb, anti, TPO, anti-TG. All statistical analyses were carried out using the SPSS 22.0 statistical software (SPSS, Chicago, IL, USA) or Graph Pad prism 8.0 The significance levels were; ${ }^{*}=<0.05 ;{ }^{* \star} p=<0.01 ; * \star \star p=<0.001$, ${ }^{\star \star \star \star} p=<0.0001$.

\section{Results}

At treatment with radioiodine 204 patients were registered and thyroid antibodies; TRAb, anti-TPO, anti TG were analyzed before treatment with radioiodine, and 3 months after radioiodine the antibody analysis was repeated for detection of patients that showed an increase of 1.1 or more. The cut of was set based on the knowledge of the variation coefficient for the antibody assays. We found two groups according to antibody response 3 months after radioiodine; one group increased in TRAb (70\% of patients) and some of these also increased in anti-TPO, and anti-TG. Another group showed a decrease in antibodies or were unchanged (30\% of patients) (Fig. 1). There was not only a significant increase or decrease in fold change 3 months after radioiodine, but also a significant increase or decrease in median values of all three antibodies (Fig. 1). Three months after treatment, a correlation with radioiodine was found for TRAb and anti-TPO (Fig. 2) but not for anti-TG (data not shown). 
All 204 patients were followed for at least 1 year after treatment with radioiodine to identify the development of $\mathrm{GO}$ and correlate $\mathrm{GO}$ to the antibody response. We found an overrepresentation of $\mathrm{GO}$ in the group with increased TRAb and anti-TPO with a proportion of GO patients at follow-up after 1 year of $70 \%$ versus $30 \%$ in the group with no increase in antibodies three months after radioiodine (Fig. $3 \mathrm{~A}$ ). If we excluded those patients with GO and low or unchanged TRAb or anti-TPO (Fig. 3B) who had received treatment with prednisolone the effect of antibodies was more pronounced with a proportion of GO of $80 \%$ versus $20 \%$ for TRAb and similar proportions for anti-TPO (Fig. 3B). When analyzing GO patients for TRAb and anti-TPO the median values were significantly different, with higher values in the group of GO patients with increased TRAb compared with unchanged or lower values (Fig. 3C). If dividing the material in patients with or without GO the median TRAb was significantly higher in patients with $\mathrm{GO}$ and the majority of patients with GO have antibody levels above the median of the entire material (Fig. 3D)

We also tried to define an association of increase or decrease in antibodies and clinical parameters previously associated with the incidence of GD, e.g. sex, ethnic background, smoking and age, but we found no correlation with these parameters (Table 1). We also studied factors that might affect treatment with radioiodine (treatment dose, duration of disease, primary treatment) and found no factor that affected the antibody response (Table 1). Lastly we also studied factors that might increase the presence and risk of GO (smoking, duration of GO, treatment with steroids), these were not different between the antibody response groups (Table 1 ).

\section{Genotyping of Graves' patients treated with radioiodine}

We analyzed SNPs in HLA, CTLA-4 and CYR61 in patients $(n=127)$ treated with radioiodine (Table 2) to define the genetic background in the development of $G O$ and antibody response of TRAb, anti-TPO and anti-TG. The response was divided into patients with increased or decreased antibodies 3 months after radioiodine. There was no significant difference in the presence of described SNPs between these groups nor did we detect a significant difference between patients with or without $\mathrm{GO}$, although the allele frequency was lower in patients with GO (OR 0.56, p = 0.07) (Table 3). However, when analyzing the material by dividing TRAb levels into groups above and below median (15 IU/L) after treatment with radioiodine, the allele frequency of the rs 231775 SNP in CTLA4 was significantly changed between groups (OR 0.48, $p=0.005$ ) and associated with TRAb above the median which was confirmed by linear regression analysis of TRAb (data not shown), which was in contrast to anti-TPO and anti-TG which showed no significant association (Table 3).

Table 3. SNPs in GD patients treated with radioiodine A. Association with TRAb below and above median $15 \mathrm{IU} / \mathrm{L}$. B. Association with GO. 


\begin{tabular}{|c|c|c|c|c|c|c|}
\hline \multirow[t]{2}{*}{ Gene } & \multirow[t]{2}{*}{ SNP } & $\begin{array}{l}\text { Allele } \\
\text { Frequency } \\
\text { TRAb (IU/L) }\end{array}$ & $\begin{array}{l}\text { Allele } \\
\text { Frequency } \\
\text { TRAb (IU/L) }\end{array}$ & $\begin{array}{l}\text { Associated } \\
\text { Allele }\end{array}$ & $\begin{array}{l}\text { OR for } \\
\text { associated } \\
\text { allele }(95 \% \mathrm{Cl})\end{array}$ & \multirow[t]{2}{*}{$p$-value } \\
\hline & & $\begin{array}{l}\bigotimes \text { median (15 } \\
\text { IU/L) }\end{array}$ & $\begin{array}{l}\geq \text { median } \\
(15 \mathrm{IU} / \mathrm{L})\end{array}$ & & & \\
\hline CYR61 & rs1378228 & 0.35 & 0.39 & $\mathrm{~T}$ & $\begin{array}{l}1.19(0.72- \\
1.99)\end{array}$ & 0.500 \\
\hline \multirow[t]{2}{*}{ CTLA4 } & rs3087243 & 0.37 & 0.42 & $A$ & $\begin{array}{l}1.28(0.77- \\
2.12)\end{array}$ & 0.334 \\
\hline & rs231775 & 0.46 & 0.29 & G & $\begin{array}{l}0.48(0.28- \\
0.80)\end{array}$ & 0.005 \\
\hline $\begin{array}{l}\text { HLA- } \\
\text { DRB1 }\end{array}$ & rs6457617 & 0.42 & 0.42 & C & $\begin{array}{l}1.30(0.794- \\
2.14)\end{array}$ & 0.295 \\
\hline
\end{tabular}

B

\begin{tabular}{|lllllll|}
\hline Gene & SNP & $\begin{array}{l}\text { Allele Frequency } \\
\text { in patients } \\
\text { without GO }\end{array}$ & $\begin{array}{l}\text { Allele } \\
\text { Frequency in } \\
\text { patients with } \\
\text { GO }\end{array}$ & $\begin{array}{l}\text { Associated } \\
\text { Allele }\end{array}$ & $\begin{array}{l}\text { OR for } \\
\text { associated } \\
\text { allele (95\% } \\
\text { Cl) }\end{array}$ & p-value \\
\hline CYR61 & rs1378228 & 0.36 & 0.4 & T & 1.181 & 0.58 \\
\hline CTLA4 & rs3087243 & 0.37 & 0.48 & A & 1.62 & 0.10 \\
\cline { 2 - 4 } & rs231775 & 0.41 & 0.28 & G & 0.56 & 0.07 \\
\hline $\begin{array}{l}\text { HLA- } \\
\text { DRB1 }\end{array}$ & & & 0.53 & C & 1.56 & 0.13 \\
\hline
\end{tabular}

\section{Discussion}

Strong risk factors for development of GO are treatment with radioiodine and smoking, but mechanisms for the effects are, in most cases, not defined. The link between changes in thyroid tissue after radioiodine and orbital tissues is unknown. We have shown that 3 months after treatment with radioiodine, two groups of patients were identified according to antibody response, one group that did not increase in TRAb, anti-TPO and anti-TG (approximately $30 \%$ of the patients) and one group that increased in antibodies (approximately $70 \%$ of the patients). This has previously been demonstrated in a smaller group of GD patients [15]. The second observation was that the risk of developing GO was clearly elevated in patients which increased in TRAb 3 months after radioiodine. The third observation was that patients with a polymorphismn in CTLA4 developed higher titres of TRAb than in patients without this polymorphism. Laurberg et al, have previously shown that radioiodine treatment increases TRAb already 
1 month after treatment and with a maximal response after three months [8]. We have found two subgroups, one subgroup does not increase in antibodies and the other group increased in thyroid antibodies after treatment with radioiodine. The latter group might be important to identify because prednisolone is most often given to all risk patients at start of radioiodine to prevent GO. Here we show that GO preferentially develops in the group that increases in thyroid antibodies after 3 months which indicates that this group should receive pre-treatment with prednisolone. In our study, we have treated risk patients with prednisolone at start of radioiodine with a decrease of prednisolone 1 month later and with termination after 3 months when antibodies are at maximal levels, and the prednisolone dose is low. Further studies are needed to define the kinetics of the increase in TRAb which might result in new routines for pre-treatment with prednisolone.

We and others have previously shown that treatment with radioiodine increases the risk of developing GO, but the mechanism has not been defined $[7,17,18]$. Here we show that the link between, the thyroid and the orbita tissue might be a release of TRAb and anti-TPO presumably from infiltrating immunocompetent cells of the thyroid, which later affect the orbital tissue in risk patients. One possible mechanism is that radioiodine decreases all immunocompetent cells, but the antibody producing cells have a higher proliferation rate than immunosuppressive cells, which might result in an imbalance between the described cells with an uncontrolled release of thyroid antibodies. In vitro it has been shown that a mixture of immunocompetent cells in Hashimoto produces thyroid specific antibodies after irradiation, and this effect was dose dependent [11]. We have previously studied the effect of the dose of radioiodine, but we could not confirm this in vivo [15]. Another hypothesis is that a transient increase in thyroid antigen like thyroglobulin will be released when cells are destroyed by irradiation $[9,10]$. However, we found no association between TRAb and thyroglobulin compared with TRAb and anti-TPO after treatment with radioiodine. Also in some cases thyroid antibodies might persist for several years after radioiodine which indicates that other mechanisms exist.

Another strong risk factor for autoimmune thyroiditis (AIT), GD and GO is active smoking [3]. We and others have shown that TRAb persists at higher levels than non-smokers during treatment with methimazole [4]. In orbital tissues we have studied other risk factors for $\mathrm{GO}$ and found that smokers have increased expression of CYR61 [14]. Smoking is not only a risk factor for AIT but also for other autoimmune diseases like rheumatoid arthritis, these patients show higher activity parameters in smokers [19].

It is well established that HLA and CTLA-4 are associated with GD, but there is lack of a specific genotype to GO. However, in a previous microarray we have shown that a matrix protein, CYR61, is increased in patients with severe $\mathrm{GO}$ in active phase with a decrease in the chronic phase [12]. We have also shown in another microarray of orbital tissue that CYR61 is preferentially increased in smokers compared with nonsmokers [14]. In a genotyping study, we have demonstrated an increased risk of developing GO in smokers with an association with CYR61 [13]. 
In the present study, we have found a new association of TRAb elevated above the median and rs 231775 in CTLA-4. The variant is located in exon $1+49$ and it was shown that the $\mathrm{A}$ to $\mathrm{G}$ substitution at this location is linked with GD [20]. A study by Ban et al. found that the presence of the genotype GG in the CTLA4 $A / G_{49}$ SNP resulted in reduced increase in T-cell proliferation when compared with the AA genotype [21].

Furthermore a previous study showed that a gene polymorphism in CTLA-4 contributes to the pathogenesis of GD because when peripheral blood cells were incubated with a monoclonal anti-human CTLA-4 monoclonal antibody resulted in increased blood cell proliferation [22]. It has also been demonstrated that a splice variant of CTLA-4 results in the release of a soluble form of CTLA-4 with increased levels in serum from patients with GD and that this soluble form bind to CD80/CD86, resulting in inhibition of T-cell activation [23]. Later it was shown that increased concentration of soluble CTLA-4 correlates with the severity of $\mathrm{GO}$ and that a genetic variation in the CTLA-4 gene region partially determines the level of its soluble form [24]. Other autoimmune conditions, like myasthenia gravis, SLE, coeliac disease and type 1 diabetes, are associated with soluble forms of CTLA-4, which has been reviewed by Saverino et al [25]. However, no study describes an association between a SNP in CTLA-4 and increased autoantibodies as in our study with increased TRAb.

To conclude we have demonstrated that the increase in TRAb after treatment with radioiodine of GD patients without GO is associated with later development of GO compared to a group that does not increase in TRAb. Also we have demonstrated that a genetic variation in CTLA-4 is associated with higher levels of TRAb after treatment with radioiodine.

\section{Declarations}

\section{Acknowledgements}

We are grateful to the nurses at department of Oncology for the help with the blood tests and Perparim Cerri for amplification of DNA.

\section{Author contributions}

The authors Mikael Lantz and Ola Lindgren treated these patients and collected data and DNA

Bushra Shahida and Vijayachitra Modhukur genotyped all patients and performed bioinformatic analysis All authors has made a substantial contribution to the design of the study, acquisition and interpretation of data, as well as revising it critically for important intellectual content.

\section{Funding}

This work was supported by grants from the Faculty of Medicine at Lund University, the Påhlsson foundation, the Skåne Research Foundation and the Research Funds of Skåne University Hospital 


\section{Compliance with ethical standards}

\section{Conflict of Interest Disclosure}

Bushra Shahida declares that she has no conflict of interest.

Kleoniki Tsoumani declares that she has no conflict of interest.

Tereza Planck declares that she has no conflict of interest.

Vijayachitra Modhukur declares that she has no conflict of interest

Pernilla Asp declares that she has no conflict of interest.

Anna Sundlöv declares that she has no conflict of interest.

Jan Tennvall declares that he has no conflict of interest.

Peter Åsman declares that he has no conflict of interest.

Ola Lindgren declares that he has no conflict of interest.

Mikael Lantz declares that he has no conflict of interest.

\section{Consent to participate}

The patients provided written informed consent for disclosing clinical and imaging data

\section{Ethics approval}

The regional research ethics committee approved the study in Lund, Sweden (project number 160610). Informed consent was obtained from participating patient after full explanation of the purpose and nature of all procedures used.

\section{References}

1. Y. Tomer,T.F. Davies, Searching for the autoimmune thyroid disease susceptibility genes: from gene mapping to gene function. Endocrine Review 24(5), 694-717 (2003).

2. T.F. Davies. Really significant genes for autoimmune thyroid disease do not exist - so how can we predict disease? Thyroid 17(11),1027-1029 (2007).

3. W.M. Wiersinga. Smoking and thyroid. Clin Endocrinol 79(2), 145-151 (2013).

4. M. Lantz, J. Calissendorff, F. Träisk, L. Tallstedt, T. Planck, O. Törring, B. Hallengren, P. Åsman . Adjuvant treatment of Graves' disease with diclofenac - safety, effects on ophthalmopathy and antibody concentrations. Eur Thyroid J 5(1), 50-57 (2016). 
5. D.H.C. Khoo, S.C. Ho, L.L. Seah, K.S. Fong, E.S. Tai, S.P. Chee, P.H.K. Eng, S.E. Aw, A.C.K. Fok. The combination of absent thyroid peroxidise antibodies and high thyroid-stimulating immunoglobulin levels in GD identifies a group at markedly increased risk of ophthalmopathy. Thyroid 9(12), 11751180 (1999).

6. M. Lantz, T. Planck, P. Åsman, B. Hallengren. Increased TRAb and/or low anti-TPO titers at diagnosis of Graves' disease (GD) are associated with an increased risk of developing ophthalmopathy after onset of GD. Experimental Clinical Endocrinology \& Diabetes 122(2), 113-118 (2014).

7. F. Träisk, M. Abraham-Nordling , G. Berg, J. Calissendorff, B. Hallengren, P. Hedner, M. Lantz, E. Nyström, L. Tallstedt, A. Taube, O. Törring, G. Wallin, P. Åsman, G. Lundell. Thyroid associated ophthalmopathy ocurrence after treatment for Graves' hyperthyroidism with iodine-131 or antithyroid drugs . J Clin Endocrinol Metab 94(10), 3700-3707 (2009).

8. P. Laurberg, G. Wallin, L. Tallstedt, M. Abraham-Nordling , G. Lundell, O. Törring. TSH-receptor autoimmunity in Graves's disease after therapy with anti-thyroid drugs, surgery, or radioiodine: a 5 year prospective randomized study. European J Endocrinol 158(1), 69-75 (2008).

9. S. Atkinson, A.M. McGregor, P. Kendall-Taylor, M.M. Peterson, B.R. Smith. Effect of radioiodine on stimulatory activity of Graves' immunoglobulins. Clinical Endocrinology 16(6), 537-543 (1982).

10. C.S. Teng, R.T. Yeung, R.K. Khoo, T.T. Alagaratnam. A prospective study of the changes in thyrotropin binding inhibitory immunoglobulins in Graves' disease treated by subtotal thyroidectomy or radioactive iodine. J Clin Endocrinol Metab 50(6), 1005-1010 (1980).

11. A.M. McGregor, B. Rees Smith, S. McLachlan, R. Hall. Effect of irradiation on thyroid- antibody production. Lancet 2(8140), 442-444 (1979).

12. M. Lantz, T. Vondrichova, H. Parikh, C. Frenander, M. Ridderstråle, P. Åsman P, M. Åberg,L. Groop, B. Hallengren. Overexpression of immediate early genes in active Graves' ophthalmopathy. J Clin Endocrinol Metab 90(8)4784-4791 (2005).

13. T. Planck, B. Shahida, M. Sjögren, L. Groop, B. Hallengren, M. Lantz. Association of polymorphisms in CTLA4, BTG2, CYR61, ZFP36 and SCD with Graves' disease and ophthalmopathy. Thyroid 24(7), 1156-1161 (2014).

14. T. Planck, B. Shahida, H. Parikh, K. Ström, P. Åsman, H. Brorson, B. Hallengren, M. Lantz. Immediate early genes are overexpressed in smokers with Graves'ophthalmopathy compared to non-smokers. Thyroid 24(10), 1524-1532 (2014).

15. O. Lindgren, P. Asp, A. Sundlöv, J. Tennvall, B. Shahida, T. Planck, P. Åsman, M. Lantz. The effect of radioiodine treatment on TRAb, anti-TPO and anti-TG in Graves' disease. European Thyroid Journal 8(2), 64-69 (2019).

16. M.J. Simmonds, S.C.L. Gough. Unravelling the genetic complexity of autoimmune thyroid disease: HLA, CTLA-4 and beyond. Clinical \& Experimental Immunology 136(1), 1-10 (2004).

17. L. Bartalena, C. Marcocci, F. Bogazzi, L. Manetti L, M.L. Tanda, E. Dell Unto E, G. Bruno-Bossio, M. Nardi , M.P. Bartolomei, A. Lepri, G. Rosso, E. Martino, A. Pincera. Relation between therapy for hyperthyroidism and the course of Graves'ophthalmopathy. N Engl J Med 338(2), 73-78 (1998). 
18. L. Tallstedt, G. Lundell, O. Torring, G. Wallin, J.G. Ljunggren, H. Blomgren, A. Taube. Occurrence of opthalmopathy after treatment for Graves'hyperthyroidism. The thyroid study group. N Engl L Med 326(26), 1773-1788 (1992).

19. M.A. Gianfrancesco, L. Trupin, S. Shiboski, M. Van der Laan, J. Graf, J. Imboden, J. Yazdany, G. Schmajuk. Smoking is associated with disease activity in rheumatoid arthritis: A longitudinal study controlling for time-varying covariates. J Rheumatol 46(4), 370-375 (2019).

20. Y. Tu, G. Fan, Y. Dai Y, T. Zeng, F. Xiao, L. Chen, W. Kong. Association between rs3087243 and rs231775 polymorphism within the cytotoxic T-lymphocyte antigen 4 gene and Graves' disease: a case/control study combined with meta-analyses. Oncotarget 8(66), 110614-110624 (2017).

21. Y. Ban, T.F. Davies, D.A. Greenberg, A. Kissin, B. Marder, B. Murphy, et al. Analysis of the CTLA-4, CD28, and inducible costimulator (ICOS) genes in autoimmune thyroid disease. Genes \& Immunity 4(8), 586-93 (2003).

22. T. Koukki, Y. Sawai, C.A. Gardine, M. Fisfalen, M. Alegre, L.J. De Groot. CTLA-4 gene polymorphism at position 49 in exon 1 reduces the inhibitory function of CTLA-4 and contributes to the pathogenesis of Graves' disease. J Immunol 165(11):6606-6611 (2000).

23. D. Saverino, R. Brizzolara, R. Simone, A. Chiappori, F. Militenda-Floriani, G. Pesce, M. Bagnasco. Soluble CTLA-4 in autoimmune thyroid diseases: relationship with clinical status and possible role in the immune response dysregulation. Clin Immunol 123(2): 190-198 (2007).

24. J. Daroszewski, E. Pawlak, I. Karabon, I. Frydecka, A. Jonkisz, M. Slowik, M. Bolanowski. Soluble CTLA-4 receptor an immunological marker of Graves' disease and severity of ophthalmopathy is associated with CTLA-4 Jo31 and CT60 gene polymorphisms. Eur J Endocrinol 161(5):787-793 (2009).

25. D. Saverino, R. Simone, M. Bagnasco, G. Pesce. The soluble CTLA-4 receptor and its role in autoimmune diseases: an update. Auto Immun Highlight 1(2): 73-81 (2010).

\section{Figures}


Figure 1
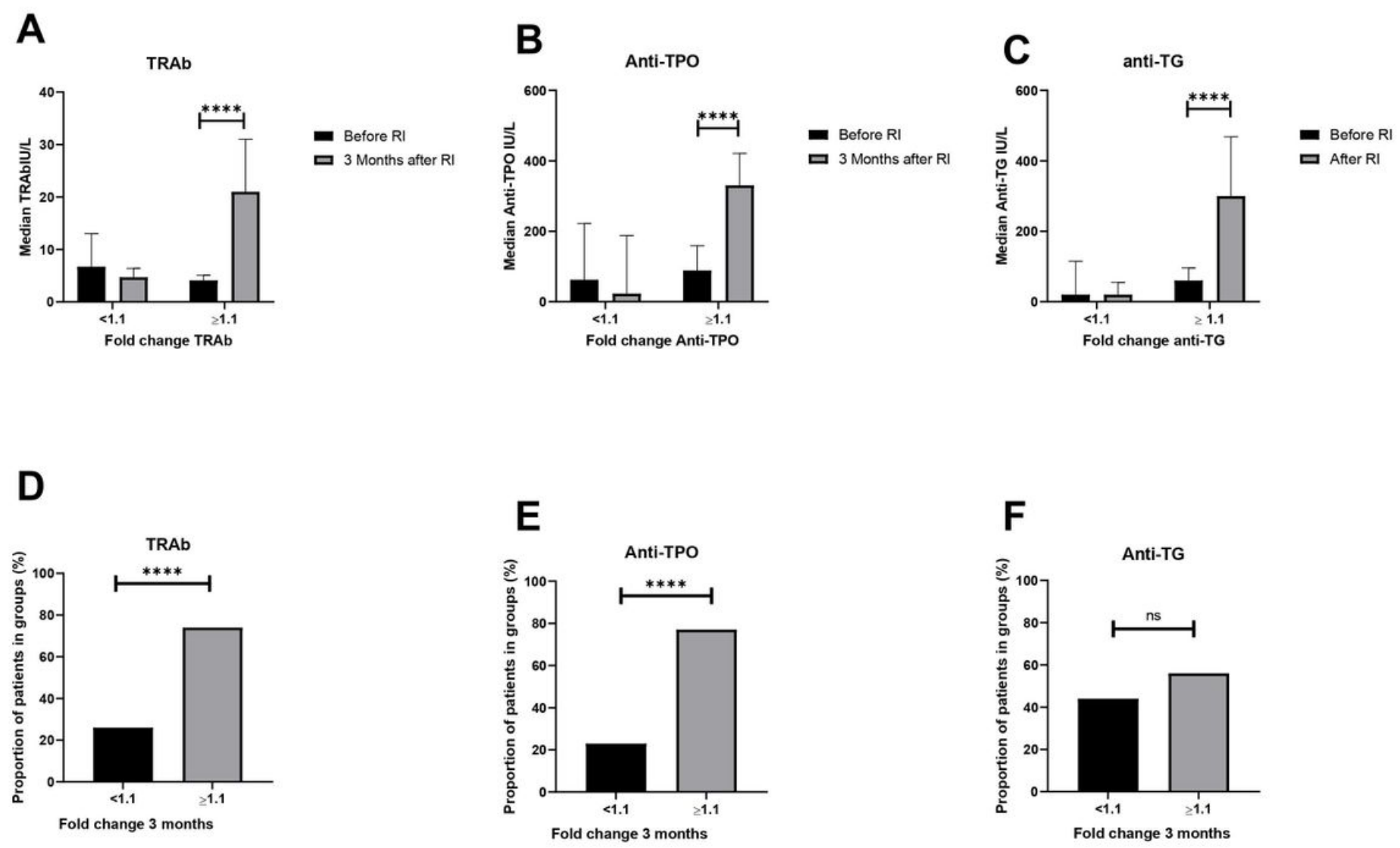

Figure 1

Fold change and proportion of TRAb (A, D), anti-TPO (B, E) and anti-TG (C, F) 3 months after treatment of Graves' disease with radioiodine. The median values of TRAb, anti-TPO and anti TG before and after radioiodine in the group with fold change $<1.1$ and in the group with fold change $>/=1.1$ were all significant with $p$-values $<0.0001$ (t-test). Differences in proportion was calculated with a binomial test and differences in median values with a t-test. 
Figure 2

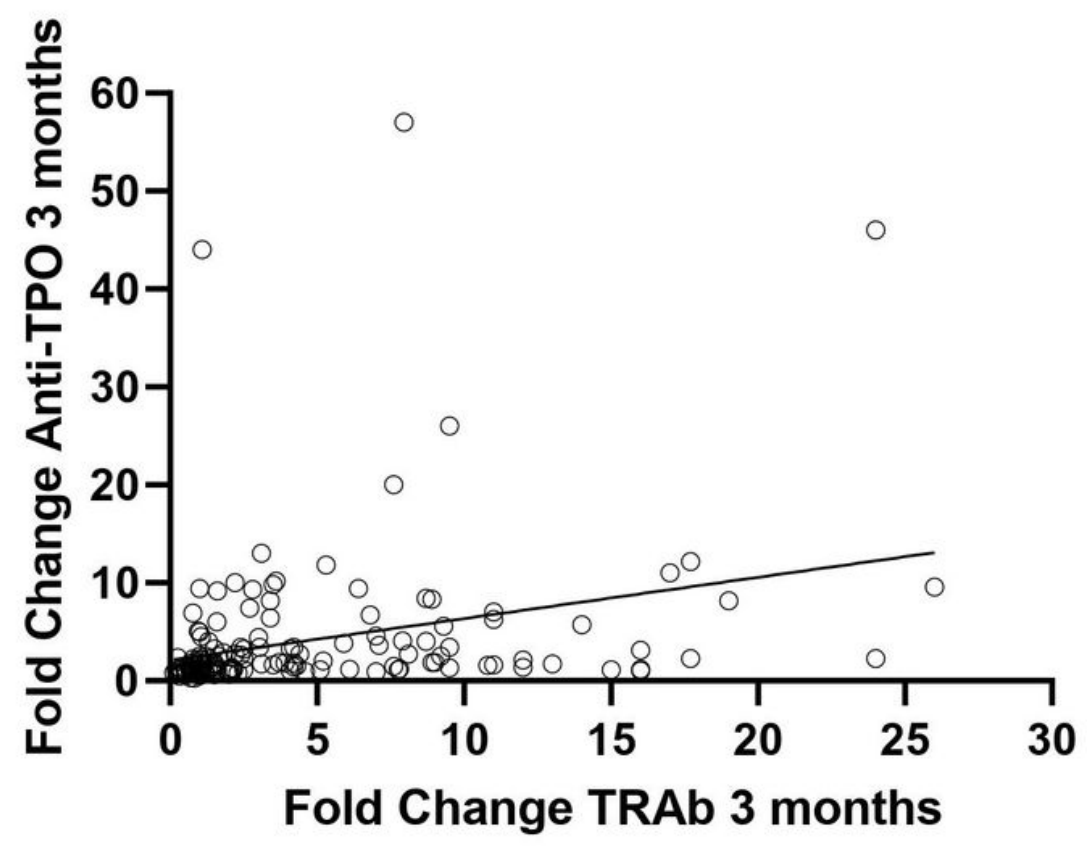

Figure 2

Correlation of fold change in TRAb and anti-TPO three months after treatment with $\mathrm{RI}(\mathrm{R}=0.362, \mathrm{p}<$ 0.0001) 


\section{Figure 3}
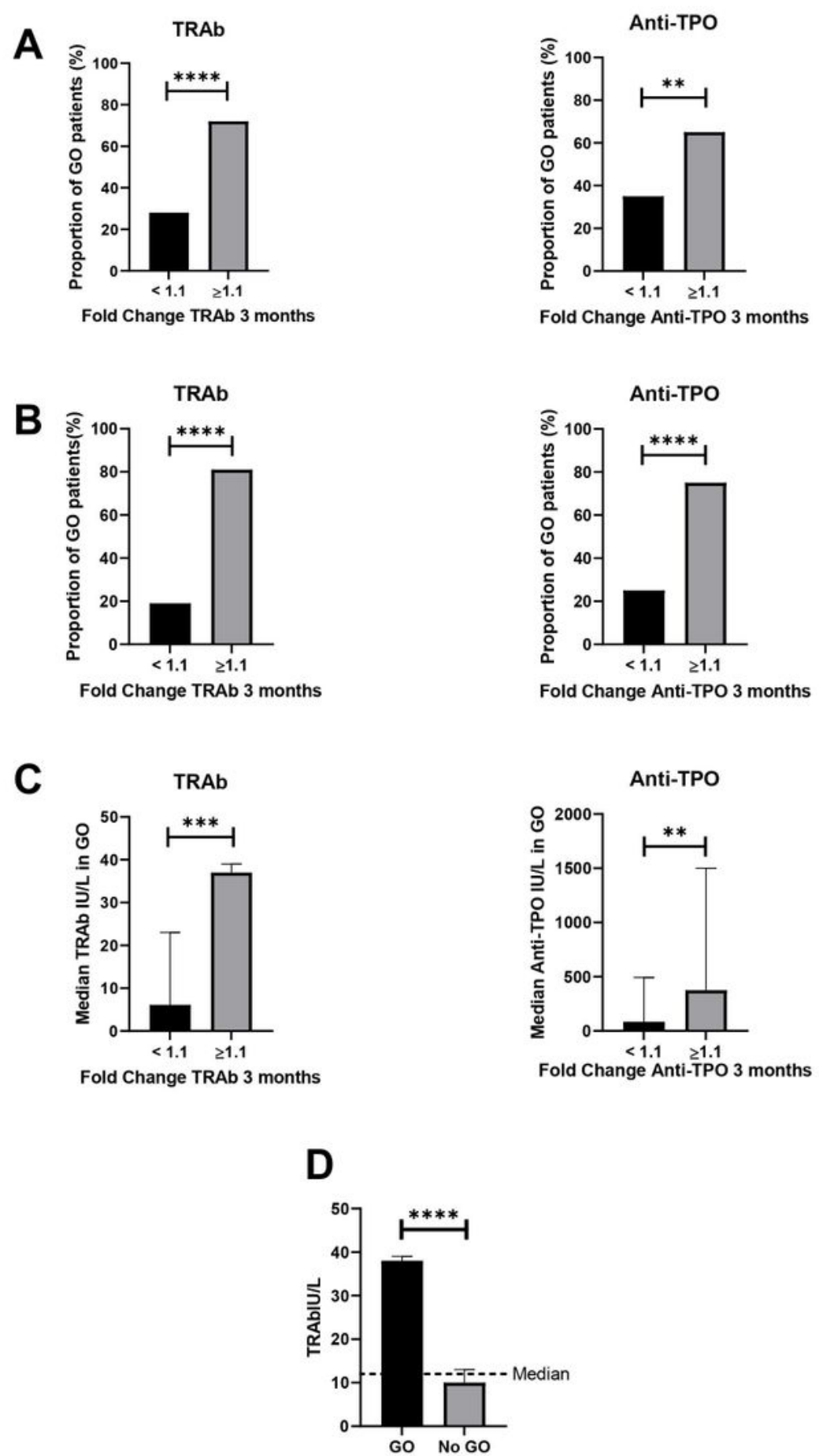

\section{Figure 3}

Development of Graves' ophthalmopathy 1 year after RI in the whole group. A. increased TRAb $(n=32)$ or anti-TPO ( $n=23)$ compared with no increase in TRAb or anti-TPO, 3 months after RI. Proportion of all GO patients in TRAb $(n=32)$ or anti-TPO $(n=23)$ including prednisolone treated patients in the group with no increase in antibodies. B. proportion of patients where prednisolone treated patients were excluded in the group with no increase in TRAb $(n=26)$ or anti-TPO $(n=20)$. C. GO patients with median values of TRAb 
$(n=26)$ and anti-TPO $(n=20)$ in patients 3 months after radioiodine treatment. D. Median values of TRAb in patients with and without $\mathrm{GO}$ with a dotted line which show the median value of TRAb in all patients. Differences in proportion was calculated with a binomial test and differences in median values the t-test was used. Significance is shown in figures. 